\title{
əImpact of Extreme Land Surface Heterogeneity on Micrometeorology over Spring Snow Cover
}

\author{
R. MOTT \\ WSL Institute for Snow and Avalanche Research SLF, Davos, Switzerland, and Institute of Meteorology and Climate Research, \\ Atmospheric Environmental Research (KIT/IMK-IFU), KIT-Campus Alpin, Garmisch-Partenkirchen, Germany

\section{S. SCHLÖGL} \\ WSL Institute for Snow and Avalanche Research SLF, Davos, and Laboratory of Cryospheric Sciences, \\ School of Architecture, Civil and Environmental Engineering, École Polytechnique \\ Fédérale de Lausanne, Lausanne, Switzerland

\section{DIRKS} \\ WSL Institute for Snow and Avalanche Research SLF, Davos, Switzerland

\section{LEHNING} \\ WSL Institute for Snow and Avalanche Research SLF, Davos, and Laboratory of Cryospheric Sciences, School of Architecture, \\ Civil and Environmental Engineering, École Polytechnique Fédérale de Lausanne, Lausanne, Switzerland
}

(Manuscript received 1 May 2017, in final form 25 July 2017)

\begin{abstract}
The melting mountain snow cover in spring typically changes from a continuous snow cover to a mosaic of patches of snow and bare ground, inducing an extreme heterogeneity of the land surface. A comprehensive measurement campaign, the Dischma experiment, was conducted during three entire ablation seasons. The aim of this study was to experimentally investigate the small-scale boundary layer dynamics over a melting snow cover with a gradually decreasing snow cover fraction and the associated heat exchange at the snow surface. This study presents a unique dataset combining eddy covariance measurements at different atmospheric levels with maps of snow surface temperatures and snow cover fractions. The experiments evidence diurnal mountain wind systems driving the diurnal cycle of turbulent sensible heat fluxes over snow and the formation of katabatic flows over longlasting snow patches strongly affecting the temporal evolution of snow surface temperature patterns. The snow cover distribution is also shown to be of vital importance for the frequency of stable internal boundary layer development over snow. For situations with a clear evidence of stable internal boundary layer development over snow, the data reveal a very shallow atmospheric layer adjacent to the snow cover decoupled from the warm-air advection above. These measurements confirm previous wind tunnel experiments that also evidenced a decoupling of the air adjacent to the snow cover from the warmer air above, especially within topographical depressions and when ambient wind velocities are low. For these situations, in particular, all tested energy balance models strongly overestimated the turbulent sensible heat flux directed toward the snow cover.
\end{abstract}

\section{Introduction}

The strong interaction between the near-surface atmosphere and the underlying ground via heat exchange

D Denotes content that is immediately available upon publication as open access.

Corresponding author: Rebecca Mott, mott@slf.ch processes makes the presence of snow a key component of the Earth system (Sauter and Obleitner 2015) with vital consequences for the hydrological cycle (Lehning 2013). Furthermore, snow albedo feedbacks are shown to enhance large- and small-scale variability of atmospheric warming and even change diurnal wind systems (Randall et al. 1994; Letcher and Minder 2015).

The springtime snow cover typically changes from a continuous snow cover to a mosaic of patches of snow 
and bare ground, inducing an extreme heterogeneity of the land surface (Liston 1995). In the absence of terrain, strong snow cover variations drive a snow-breeze type of circulation, responding to the strong thermal contrast between snow and bare ground (Johnson et al. 1984; Taylor et al. 1998). In mountainous regions, where springtime snow cover is mainly governed by complex terrain and elevation gradients, snow-breeze circulations and diurnal mountain wind systems interact (Letcher and Minder 2017). Segal et al. (1991) showed that the presence of snow at higher elevations can counteract the diurnal upslope flow. Recent numerical results presented by Mott et al. (2015) have suggested that the presence of snow patches in spring significantly affects the diurnal mountain wind system. Thermally driven small-scale flow features are shown to develop over large snow patches, considerably changing the heat exchange process over the springtime snow cover. Furthermore, the special setup of the land surface in spring coincides with steps in surface roughness and surface temperature, inducing the development of dynamic and thermal internal boundary layers. As a result, mass and energy fluxes as well as the mean flow field characteristics show a high spatial variability not only in the horizontal but also in the vertical direction (Essery 1999; Essery et al. 2006; Granger et al. 2006; Mott et al. 2013; Harder et al. 2017).

Long-lasting snow and ice patches are typically found in topographic depressions because of preferred snow accumulation and suppressed snow ablation in sheltered areas (Tabler 1975; Dadic et al. 2010; Mott et al. 2014; Odegard et al. 2017). Large snow patches can significantly alter the near-surface flow field (Glazirin et al. 2004), and strong atmospheric decoupling and connected suppression of heat exchange slows down snow ablation in spring (Fujita et al. 2010). Recent wind tunnel experiments (Mott et al. 2016) on flow development over a melting snow patch gave evidence that wind sheltering effects result in atmospheric decoupling over snow and significantly suppress the turbulent heat exchange between the snow and adjacent atmosphere. Thus, atmospheric decoupling is promoted by - but at the same time counteracts-the effect of the warming of the atmosphere caused by heating of already snow-free areas. The interaction between these two counteracting processes is very complex and not well understood.

In winter, turbulent heat fluxes over snow show a high sensitivity to spatially variable wind velocities induced by complex terrain (Mott et al. 2011; Pohl et al. 2006; Dadic et al. 2013; Schlögl et al. 2017). Furthermore, surface energy, mass, and momentum fluxes are strongly linked to horizontally heterogeneous land surfaces (Cohen and Rind 1991). Knowledge of the effect of spring land surface heterogeneity on local heat exchange processes and the consideration of the range of scales that needs to be accounted for remains a challenging part when attempting to represent relevant processes in, for example, Earth system modeling (de Vrese et al. 2016). There are some models that parameterize and assess subgrid fractional snow cover in global and regional models as simplified functions of snow depth, snow water equivalent, roughness length, and subgrid orography (Roesch et al. 2001; Liston 2004; Takata et al. 2003; Essery 2008; Dutra et al. 2010; Best et al. 2011; Nitta et al. 2014). The interaction between the fractional snow cover and the overlying atmosphere is, however, highly simplified. The estimation of average sensible heat by flux-gradient relationships is not valid over patchy snow cover because of the high spatial variability of air temperature and sensible heat fluxes. Close to the variable surface, constant flux layers and fully developed boundary layers do not exist and yield a high temporal and spatial variability of boundary layer characteristics on a very small scale. Local air temperature and sensible heat flux measurements are strongly dependent on the upwind distribution of snow patches and snow-free areas (Marsh et al. 1999). Experiments on heat exchange processes over patchy snow cover thus become very challenging during spring conditions. This is one reason that experimental studies on heat exchange in areas featuring extreme land surface heterogeneity such as patchy snow cover are very rare (Essery et al. 2006; Mott et al. 2013) and typically only represent a snapshot in time (Mott et al. 2013). Recent studies pointed out the necessity of field measurements conducted over a complete melting season covering the atmospheric boundary layer dynamics under different meteorological conditions and for a successively decreasing snow cover fraction, that is, increasing heterogeneity in land surface characteristics (Mott et al. 2016).

In this study, we present a unique dataset monitored during the comprehensive measurement campaign, the Dischma experiment. We present eddy covariance measurements conducted over a long-lasting snow patch in a small alpine catchment. Since measurements were performed over three complete ablation periods, the dataset comprises different snow cover distributions and meteorological conditions. Additionally, snow cover warming, snow cover distribution, and mean flow field development have been monitored throughout the three melting periods. Since recent numerical investigations on boundary flow development over patchy snow cover suggested a high sensitivity of the near-surface flow field to the changing land surface in spring (Mott et al. 2015), we will analyze turbulent heat exchange and snow cover warming as a function of the prevailing wind situation and snow cover distribution. We will further discuss the effect of a decreasing snow cover fraction on the 
boundary layer development and on the associated heat exchange above the melting snow cover.

\section{Methods}

\section{a. Field site}

The test site Gletschboden is located in the upper Dischma valley, featuring a flat area surrounded by steep slopes to the southeast and northwest, a small hill to the south, and the lower Dischma valley to the north (Fig. 1). The flat test site is located at approximately $2100 \mathrm{~m}$ MSL and is mainly covered by alpine meadow with some rocks. The Dischma valley discharges into the larger Landwasser valley, at Davos, Switzerland. The Dischma valley is approximately $15 \mathrm{~km}$ long, with the valley floor at $1600 \mathrm{~m}$ MSL at the entrance and $2000 \mathrm{~m}$ MSL at the end. Ridge-top elevations range from 2500 to $3000 \mathrm{~m}$ MSL. The Dischma valley is v-shaped and is largely symmetrical. The Dischma valley contains a $43-\mathrm{km}^{2}$ hydrological catchment with a stream meandering along the valley floor, which is fed by smaller side streams and a glacier at the southern end. High-quality runoff data are available from the federal office in Switzerland (FOEHN) for the Dischma catchment. In the 1980s, the Dischma valley was the site of an extensive field campaign, Dischmatal Klimauntersuchungen (DISKUS), which lead to several publications in the following decade regarding valley-scale meteorology (Hennemuth and Köhler 1984; Hennemuth and Schmidt 1985; Hennemuth 1986). The Dischma valley has been a site for snow hydrology studies (Lehning et al. 2006; Bavay et al. 2009; Griessinger et al. 2016). Very recently, the Dischma experiment was run in the Dischma valley from the winter season of 2013/14 until 2016/17, with the aim to investigate snow-atmosphere interactions driving snow accumulation (Gerber et al. 2017) and ablation in an Alpine catchment.

\section{b. Eddy covariance measurements}

As part of the Dischma experiment measurement campaign, a turbulence station was installed at the Gletschboden area during the ablation seasons of 2014, 2015, and 2016. For the seasons 2014 and 2015, the turbulence station consisted of two turbulence towers and was installed over a long-lasting snow patch. The turbulence towers were equipped with two Young ultrasonic anemometers mounted $0.7 \mathrm{~m}$ (in 2014) and $3.3 \mathrm{~m}$ (in 2015) above snow-free ground, two ultrasonic anemometers (CSAT3, Campbell Scientific, Inc.) mounted at $2.6 \mathrm{~m}$ (in 2014) and $2.2 \mathrm{~m}$ (in 2015) above snow-free ground, and one anemometer (DA-600, Kaijo Denki) mounted at $0.3 \mathrm{~m}$ above the snow surface.

Because of a changing snow height in winter, the height over snow changed for sensors S1 and S2 (upper level) and S3 and S4 (at medium level) during the ablation season
(Fig. 2a, Table 1). Since sensor S5 at the lowest level has been installed only on a temporary basis, the height of approximately $0.3 \mathrm{~m}$ over the snow surface could be kept constant. Furthermore, in 2015, one additional tower was been equipped with a net radiometer (CNR4) and a temperature humidity sensor (Fig. 1). Since the full energy balance station was only available for ablation period 2015, some of the analyses were only done with data recorded during this ablation season (see sections $3 \mathrm{a}$ and $3 \mathrm{~d}$ ).

The measurement setup changed for 2016 with the aim of improving footprint estimations for certain wind directions, with one turbulence tower installed over bare ground and a second one over the reference snow patch. The turbulence tower installed in the upwind snow-free area (for northerly winds) was equipped with one sonic anemometer installed at $3.2 \mathrm{~m}$ above bare ground. The turbulence tower over snow was equipped with one Young sonic anemometer at $3.5 \mathrm{~m}$ and one CSAT at $1.7 \mathrm{~m}$ above bare ground (Fig. 2a, Table 1). Sensor S5 ( $0.3 \mathrm{~m}$ above snow) was only installed during ablation days late in the ablation season. Unfortunately, predominantly southerly flows were observed during the time period when the snow cover became patchy in 2016 . The dataset is thus not usable for footprint analysis, but is used in the following to show the frequency of the development of thermal internal boundary layers.

Turbulence data were sampled at a frequency of $20 \mathrm{~Hz}$. The processing of the data to quality-controlled fluxes has been done with the Biomicrometeorology flux software (Thomas et al. 2009). The program applies plausibility tests and a despiking test after Vickers and Mahrt (1997) on the measured data. The routine further applies a time-lag correction and considers the deployment (e.g., the sonic azimuth). A frequency response correction (Moore 1986) is done and a three-dimensional rotation is performed. Finally, quality assurance/quality control (QA/QC) flags after Foken et al. (2004) are issued and fast Fourier transform power and cospectra are calculated. The change in snow height is considered in the postprocessing for every measurement day. The turbulence data were averaged to 5- and 30-min intervals. Since a comparison between different averaging times showed that the random error introduced by the choice of averaging time is rather small during daytime and larger during night and in the morning, we chose an averaging time of $30 \mathrm{~min}$ for the analysis on daytime turbulent heat fluxes applied in this study. Turbulence dataset analyzed in this study is published at the Environmental Data Portal ENVIDAT (http://www. envidat.ch/dataset/10-16904-10).

\section{c. Snow surface temperature measurements}

A thermal infrared camera (IR camera hereafter), VarioCAM HD research 900 (Infra Tec GMBH), was 

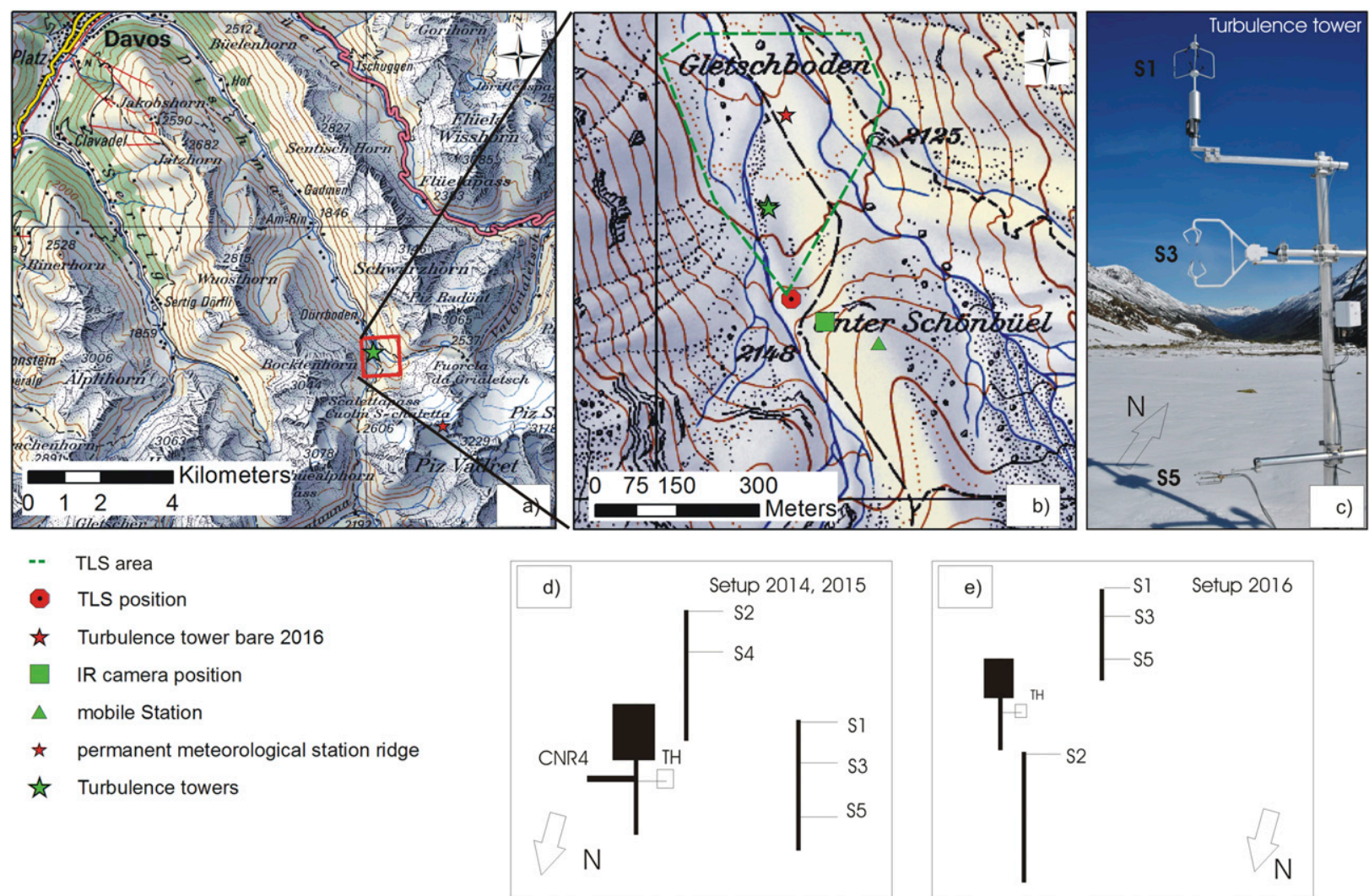

Fig. 1. (a) The upper Dischma valley (Davos, Switzerland) showing the location of (b) field site Gletschboden. (c) Picture of turbulence tower and illustrations of measurement setup in (d) 2014/15 and (e) 2016. Label descriptions: TH = temperature/humidity sensor, $\mathrm{CNR} 4=$ net radiometer, $\mathrm{S}=$ sonic anemometer.

used to measure snow surface temperatures at the Gletschboden area with a high spatial and temporal resolution. Because of the diurnal cycle of avalanche danger in the Dischma valley in spring, measurements were conducted on an hourly basis during morning hours, when the snow cover warming rates are largest.

The camera uses an uncooled microbolometer array for the detection of thermal infrared radiation in the spectral range of $7.5-14 \mu \mathrm{m}$. The resolution of the camera is $1024 \times 768$ pixels with a measurement range from $-40^{\circ}$ to $1200^{\circ} \mathrm{C}$ and an accuracy of $\pm 1.5 \mathrm{~K}$ for the measurement range. Surface temperatures measured by the IR camera were corrected according to the emissivity of snow, reflected radiation from the sky (sensed by the camera), and the atmospheric transmissivity. We used the incoming longwave radiation, vapor pressure, and air temperature from CNR4 and temperature/humidity sensors mounted at the turbulence station for the correction. The emissivity of snow was parameterized following the model of Hori et al. (2013). As the emissivity varies significantly with incident angle and snow type, an emissivity value for each pixel has been parameterized. The wavelength of peak emittance was calculated after
Wien's law for the camera temperature. The calculation of atmospheric emissivity was done with the parameterization suggested by Idso (1981), as this formulation applied specifically to the $8-15-\mu \mathrm{m}$ range of the thermal IR spectrum. Emissivity values were rather small for all measurement days, owing to the rather low temperature and relative humidity of the air. A comparison of corrected snow surface temperatures measured by the IR camera to snow surface temperatures derived from pyrgeometer measurement (CNR4 sensor) by applying the Stefan-Boltzmann law revealed a camera offset of approximately $4.5 \mathrm{~K}$. A comparison of relative temperatures obtained from the IR camera, CNR4 sensor, and a mobile weather station shows that relative values coincide well, mainly not exceeding the arbitrary threshold of $\pm 0.5 \mathrm{~K}$ (Fig. 3).

\section{d. Snow depth and snow cover fraction measurements}

In total, 44 high-resolution snow depth measurements were conducted with the terrestrial laser scanner (TLS; Riegl VZ-6000) in the three consecutive years of 2014, 2015, and 2016. We used snow depth maps of the Gletschboden with an area of $400 \mathrm{~m} \times 500 \mathrm{~m}$ (Fig. 1) in 

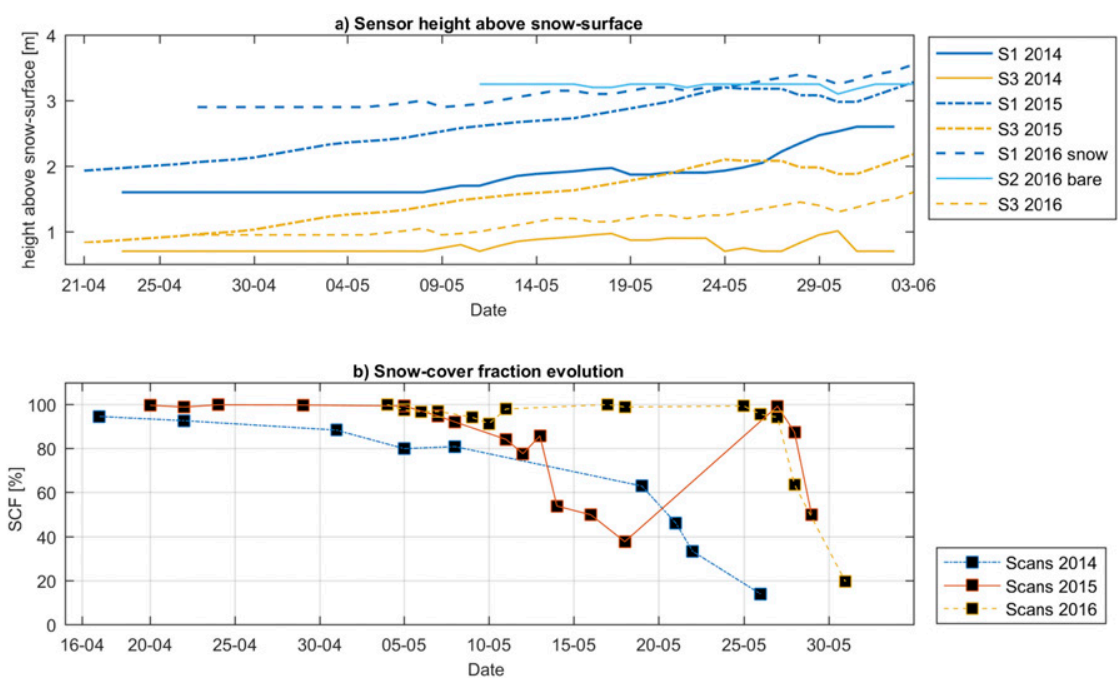

FIG. 2. (a) Sensor height above surface and (b) snow cover fractions at the field site Gletschboden, estimated from snow-depth maps obtained from terrestrial laser scans.

order to estimate the temporal development of the snow cover fraction (SCF; Fig. 2) and snow ablation rates. The Gletschboden area was recorded with a frequency of $300 \mathrm{kHz}$ and a beam divergence of $0.007^{\circ}$, which implies a horizontal resolution of approximately $0.01 \mathrm{~m}$ in $100 \mathrm{~m}$ distance from the TLS position. Scans were done at intervals of a few days depending on weather conditions, with a reduction of scan intervals to $24-48 \mathrm{~h}$ if snow ablation was very strong (Fig. 2b). A more general description of the TLS measurement setup and accuracy over snow can be found in Prokop et al. (2008), Schaffhauser et al. (2008), and Grünewald et al. (2010). We followed the postprocessing procedure described by Sommer et al. (2015), applying the multistation adjustment to improve the registration of scans conducted on different measurement days. Rasters of snow depths with a cell size of $0.2 \mathrm{~m}$ were calculated from georeferenced point clouds to estimate the snow cover fraction of the test site (Fig. 2b) and the wind fetch distance over snow at the location of turbulence measurements at the reference snow patch.

Comparing the peak snow accumulation of the three winter seasons at the nearby Weissfluhjoch location $(2540 \mathrm{~m})$ with the long-term trend (http://www. slf.ch/schneeinfo/wochenbericht/2015-16/jahresbericht/ Schneehoehenverlauf/index_DE), peak snow accumulation was below average in winter 2013/14, above average in winter 2014/15, and average in winter 2015/16. The temporal development of snow cover fractions (Fig. 2b) show a more gradual decrease in snow cover fraction at the Gletschboden and an earlier end of the ablation season in 2014 than in the consecutive years.

\section{Results}

\section{a. Prevailing wind situations and connected temporal patterns of mean turbulent heat fluxes}

Earlier numerical results show a high sensitivity of turbulent sensible heat fluxes over patchy snow cover to prevailing wind situations (Mott et al. 2015). We thus analyze temporal patterns of measured turbulent heat exchange and turbulence characteristics over the whole ablation period of 2015 for different weather classes. In this analysis, we only include data collected during the ablation period of 2015 because the full energy balance

TABLE 1. Deployed sensors, associated sensor height above ground, and year of deployment.

\begin{tabular}{|c|c|c|c|c|}
\hline \multirow[b]{2}{*}{ Sensors } & \multicolumn{4}{|c|}{ Height above snow and year of deployment } \\
\hline & 2014 & 2015 & & \\
\hline Young, (S1, S2) & $1.6-2.6 \mathrm{~m}$ & $1.9-3.3 \mathrm{~m}$ & $\mathrm{~S} 1: 3.5-2.9 \mathrm{~m}$ & $\mathrm{~S} 2: 3.2 \mathrm{~m}$ \\
\hline CSAT $(\mathrm{S} 3, \mathrm{~S} 4)$ & $0.7-1 \mathrm{~m}$ & $0.7-2.2 \mathrm{~m}$ & $\mathrm{~S} 3: 1.7-0.9 \mathrm{~m}$ & S4: No \\
\hline Kaji Denki (S5) & $0.3 \mathrm{~m}$ & $0.3 \mathrm{~m}$ & & \\
\hline CNR4 & No & $2 \mathrm{~m}$ & & \\
\hline Temperature/humidity & No & $2 \mathrm{~m}$ & & \\
\hline
\end{tabular}




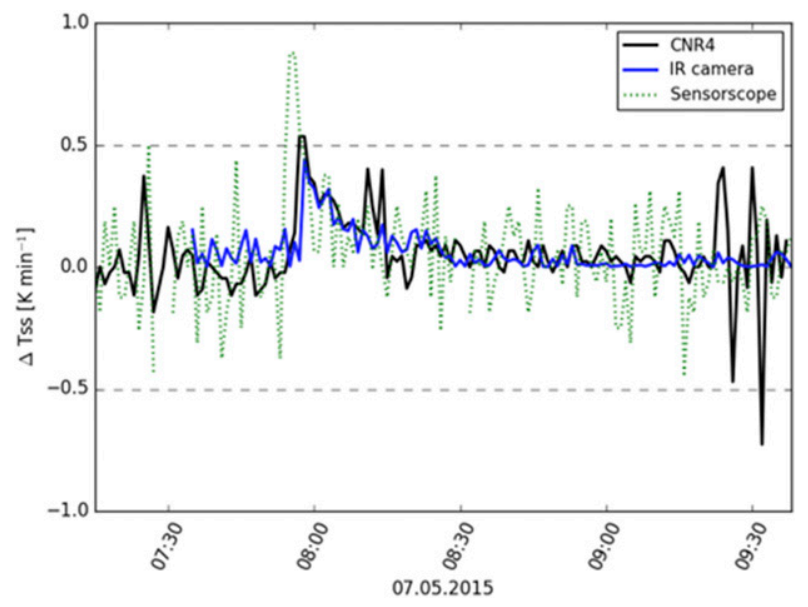

FIG. 3. Comparison of snow surface temperature change per minute for the IR camera, CNR4, and mobile weather station (Sensorscope).

station was only available for this year. The main aim of this section is to investigate the interactions among the changing land surface, the boundary layer flow, and the mean turbulent heat exchange over snow.

The diurnal variation of the median of the turbulent sensible heat flux, wind velocity, and the stability parameter $z / L$ (height above ground/Monin-Obukhov length) measured at sensors S3 and S4 (mounted at $2.2 \mathrm{~m}$ above the snow-free surface, $0.8 \mathrm{~m}$ in 2015 above the snow surface) are shown in Fig. 4 for different weather classes. Analyzing the wind system in the Dischma valley, Urfer-Henneberger and Turner (1982) suggested a categorization of the wind system into four distinct situations: undisturbed fair, Föhn, Bise, and blocking situations. Based on this analysis and considering the available data, we distinguish among ablation days characterized by synoptically induced northerly flows (Bise), thermally induced flows (undisturbed fair weather), and synoptically induced southerly flows (Föhn). Since we were only interested in the small-scale flow features, we applied a simple classification based on wind speed and wind direction to the data measured at the mobile station at the hill (Fig. 1) to categorize between synoptic north, synoptic south, and thermally induced flows. In reference to Hennemuth and Schmidt (1985), who measured valley winds up to $4 \mathrm{~m} \mathrm{~s}^{-1}$ (not averaged) in the Dischma valley, the wind speed criteria to differentiate between thermic and synoptic days was set to a mean wind velocity of $3.5 \mathrm{~m} \mathrm{~s}^{-1}$. The clear change from a mountain to valley wind was a further clear indicator to categorize the prevailing wind system as a thermally driven flow. The ablation season of 2015 included 48 days (the start of the melting season is here defined by the onset of snowmelt at the test site). Only 19 days could be clearly categorized and did not show precipitation during daytime and are thus considered in the following analysis.

\section{1) THERMALLY DRIVEN WIND SYSTEMS}

The highest sensitivity of the wind system to the change in land cover is revealed for days characterized by fair undisturbed weather, allowing the development of thermally driven wind systems (thermic class hereafter). Considering 48 days of the ablation season of 2015, $22 \%$ of the days are characterized by a thermally driven up- and down-valley wind system. The development of thermally driven wind systems is strongly connected to the change from a continuous to patchy snow cover. Thermic days are thus frequent in late spring and are observed when the sun-exposed slopes in the Dischma valley become snow-free (not shown). The strong heterogeneity of snow cover distribution results in a differentiated warming of snow-free and snow-covered slopes in the morning, which modulates the thermal contrast there and thus forces the diurnal mountain wind system. For these days, wind data evidence a change in wind direction from south (down-valley flow) to north (up-valley flow) around midday, accompanied by a significant increase in the mean wind velocity (Fig. 5). The diurnal cycle of wind direction and speed (Figs. 4a, 5) is associated with a strong diurnal cycle of the time series of the turbulent sensible heat flux (Fig. 4b). Downward turbulent sensible heat fluxes (warming the surface) are rather small during the presence of the mountain wind in the night and morning and significantly increase as the wind shifts from a down-valley to an up-valley wind. For the thermic class, stable conditions (positive stability parameter; Fig. 4d) prevail as long as the mountain winds (down-valley winds) are present. As soon as the wind turned to an up-valley wind, stratification tended to be slightly stable or even near-neutral at approximately $1.5 \mathrm{~m}$ measurement height. This weak stability is in contradiction to high positive air temperatures (Fig. 4c) and snow surface temperatures at the melting point. The strong dependency of atmospheric stability and sensible turbulent heat fluxes on the measurement height will be discussed in sections $3 \mathrm{c}$ and $3 \mathrm{~d}$.

\section{2) SyNOPTICALLY INDUCED WIND SYSTEMS}

Ablation days with evidence of synoptically induced southerly winds $(10 \%$ of ablation days; synoptic south class hereafter) are characterized by high wind velocities (Fig. 4a) and high air temperatures (Fig. 4c), most frequently observed early in the melting season when snow coverage was still high (not shown). High air temperatures and strong winds promote strongly negative turbulent sensible heat fluxes (warming the surface) during night and day with a low temporal variation (Fig. 4b). The atmospheric stability changes from near neutral during the night to stable conditions during daytime (Fig. 4d). 

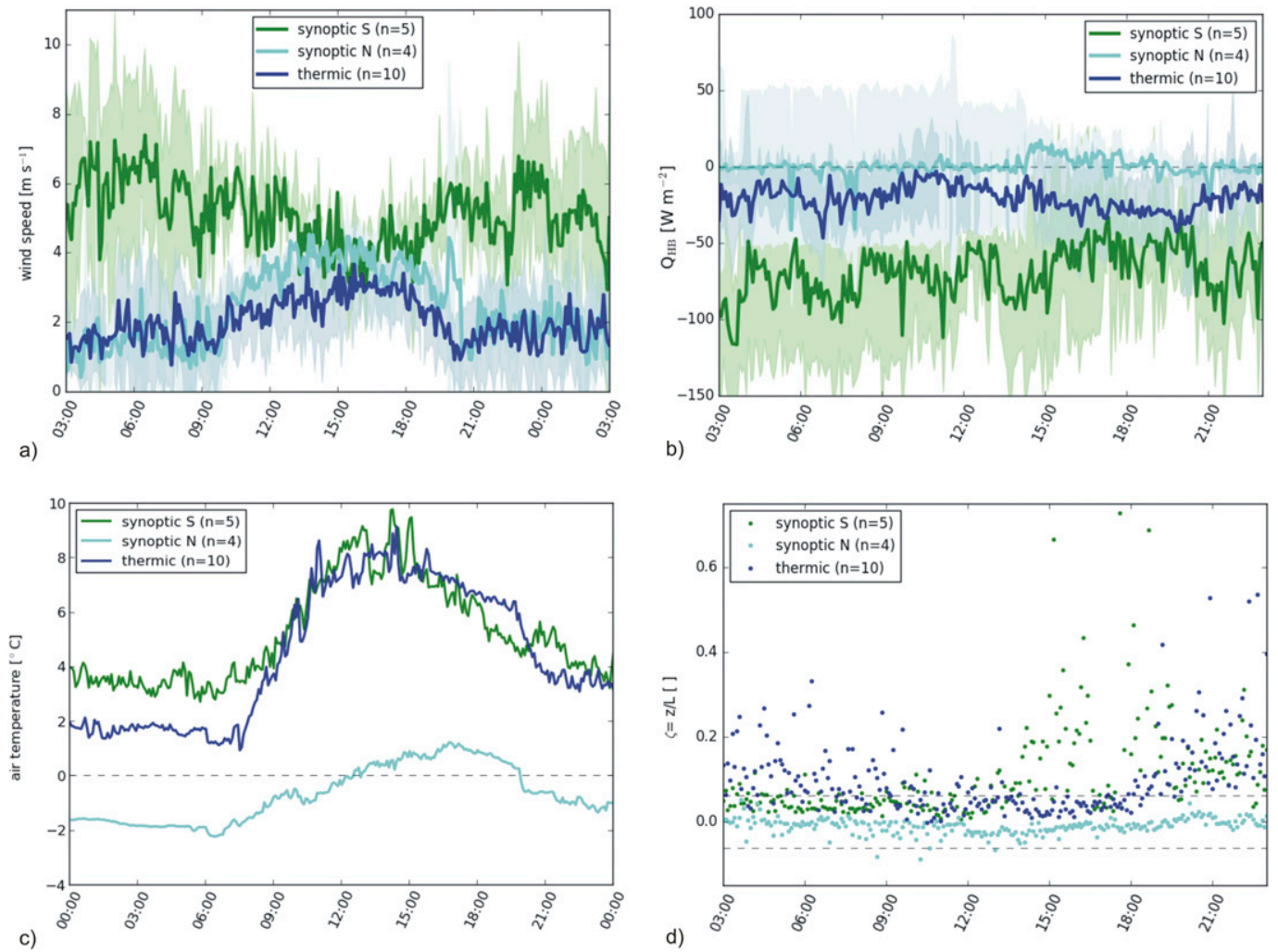

FIG. 4. Median of wind speed, median of turbulent sensible heat flux $Q_{\mathrm{HB}}$, and median of air temperature for all measurement days of the corresponding weather classes. Note that negative values of $Q_{\mathrm{HB}}$ indicate a downward heat flux warming the surface. The variability of wind speed and buoyancy flux is shown by the correspondingly colored translucent standard deviation. Median of the stability parameter $(\zeta=z / L)$ for the three weather classes, obtained from the midlevel sensors S3 and S4.

For synoptically induced northerly flows (synoptic north class hereafter), turbulent sensible heat fluxes directed toward the snow cover (negative values) are very small during daytime, fluctuating around zero in the morning. When air temperatures slightly increased above $0^{\circ} \mathrm{C}$ in the afternoon, measured sensible heat fluxes become positive (directed away from the surface) at the midlevel measurement height $(0.7-2.2 \mathrm{~m}$ above the snow-covered ground; Fig. 4b). The evidence of positive turbulent sensible heat fluxes despite positive air temperature gradients hints at a change in nearsurface thermal boundary layer conditions. The strong heterogeneity of the land surface and the associated steps in land surface temperatures induces the formation of very shallow thermal internal boundary layers. The two upper turbulence sensors are apparently above the thermal internal boundary layer adjacent to the snow cover when air temperatures are raised above the freezing point. All synoptic north situations occurred late in the ablation season when snow cover fraction was lower than $40 \%$ (not shown), favoring the development of thermal internal boundary layers above the heterogeneous land cover.
The development of thermal internal boundary layers as a function of wind direction and snow coverage is further discussed in section $3 b$.

\section{b. Prevailing wind systems and associated temporal and spatial patterns of snow surface warming}

Figure 6 shows an example of snow cover warming before (Fig. 6a) and after (Fig. 6b) sunrise on a day characterized by fair, undisturbed weather (thermic class). Two rectangles indicate areas with a strongly different response of the snow cover temperature evolution to the near-surface flow field. The average temporal evolution of snow surface temperatures for the two areas is shown for a thermic day in Fig. $6 \mathrm{c}$ and for a synoptic south day in Fig. 6d.

During the thermic day, late in the ablation season (28 May 2015), the measured snow surface temperatures at the flat Gletschboden test site show a high spatial and temporal variability (Figs. 6a,b). High-resolution snow surface temperature maps obtained from the IR camera evidence some areas featuring below-average surface temperatures in the morning (rectangle $\mathrm{B}$, marked in 


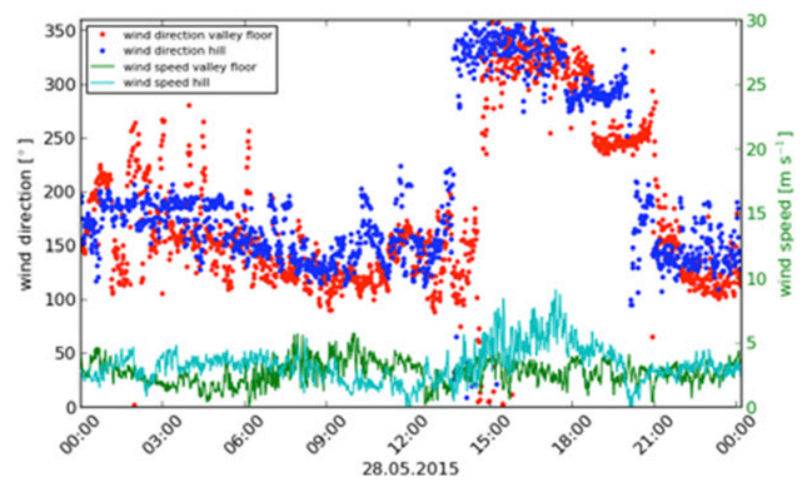

FIG. 5. Wind direction and wind velocity measured at two mobile weather stations in the Gletschboden area for a thermic day.

Fig. 6a). The temporally highly resolved sequence of measurements strongly suggests the influence of smallscale drainage flows that developed in the early morning of the thermic day (Fig. 6a). Large avalanche deposits on the northeasterly exposed slopes (not shown) apparently allowed the surface temperatures to cool more strongly than the surrounding snow-free areas during the clear night. Colder air adjacent to the snow cover finally drained down the slope, locally cooling the snow cover on the western part of the Gletschboden (rectangle B), which is visible in the surface temperature maps obtained before sunrise at 0744 UTC (Fig. 6a).

When the sun rises, observed drainage flows disappeared and shortwave radiation and increasing downward turbulent heat fluxes resulted in a rapid warming of the snow cover after 0800 UTC (Fig. 6b). Areas in the eastern part of the Gletschboden area (indicated by the rectangle A) are not affected by drainage flows in the morning and thus show higher surface temperatures before sunrise. After sunrise, however, snow cover warming is significantly lower, which is also visible in the temporal evolution of the mean surface temperature within this area shown in Fig. 6c. Small-scale spatial patterns of snow surface temperatures also reveal below-average surface temperatures at the slope of the hill Unter Schönbüel, located south of the marked area. Furthermore, smallscale stripes of very low surface temperatures at the lower part of the slope of the Unter Schönbüel (as marked in the map in Fig. 6b) indicate the influence of very smallscale flow features there. The suppression of snow cover warming within the marked area is most probably caused by the combination of wind sheltering by the small hill upstream of the test site and the low incoming shortwave radiation at the snow-covered slopes of the hill (not exposed to the sun in the morning). Thus, locally low wind velocities due to sheltering coincide with low radiative energy input.
We expect that the negative energy balance at the snow-covered northerly exposed slopes of the hill allows the temporal development of small-scale drainage flows, explaining the small stripes of very low surface temperatures. These temporally formed drainage flows thus appear to drain toward the eastern part of the Gletschboden area, cooling the snow surface at the bottom of the hill sheltered from the larger-scale, warmer, down-valley wind. On the other hand, higher wind velocities during the synoptic south class days do not allow the formation of such very small-scale drainage flows locally changing the warming rates at the snow surface (Fig. 6d). The temporal evolution of snow surface temperatures for synoptic south situations thus shows a low temporal (Fig. 6d) and spatial variability (not shown) in snow surface warming at the Gletschboden area.

\section{c. Temporal evolution of turbulent sensible heat flux profiles during a melting season responding to changes in land surface heterogeneity}

Time series of daytime turbulent heat fluxes measured at three different measurement levels (for the level heights refer to section $2 b$ ) above the snow surface are presented for the ablation seasons of 2014, 2015, and 2016 (Fig. 7). Note that the measurement setup changed in spring 2016, with one turbulence tower installed over bare ground north of the reference snow patch (Fig. 1). We only show typical time series for ablation days (air temperatures above $0^{\circ} \mathrm{C}$ ) for different snow cover distributions and with very good data quality and without precipitation. The lowest-level sensor $(0.3 \mathrm{~m}$ above ground) was only installed late in the ablation periods.

In the first stage of a melting season, as long as the snow cover is continuous (days marked by SC), daytime turbulence data during ablation days of all three years evidence downward turbulent sensible heat fluxes (negative values) at all sensor heights, indicating the presence of a deep stable atmospheric layer above the snow (Fig. 7). The vertical variability of turbulent heat fluxes is small. The second stage of a melting season starts when the snow cover distribution of the test site is dominated by the presence of a local snow line north of the Gletschboden test site in lower elevated regions (days marked by SL). During this period, the time series of turbulent flux measurements at different measurement levels showed a high sensitivity to the prevailing wind direction. For prevailing southerly winds (down-valley flows including mountain winds), all sensors measured downward turbulent sensible heat fluxes during daytime with no flux divergence (i.e., 6 and 26 May 2016). For those situations, the flow crosses very large snow-covered areas upwind of the test site featuring low heterogeneity 

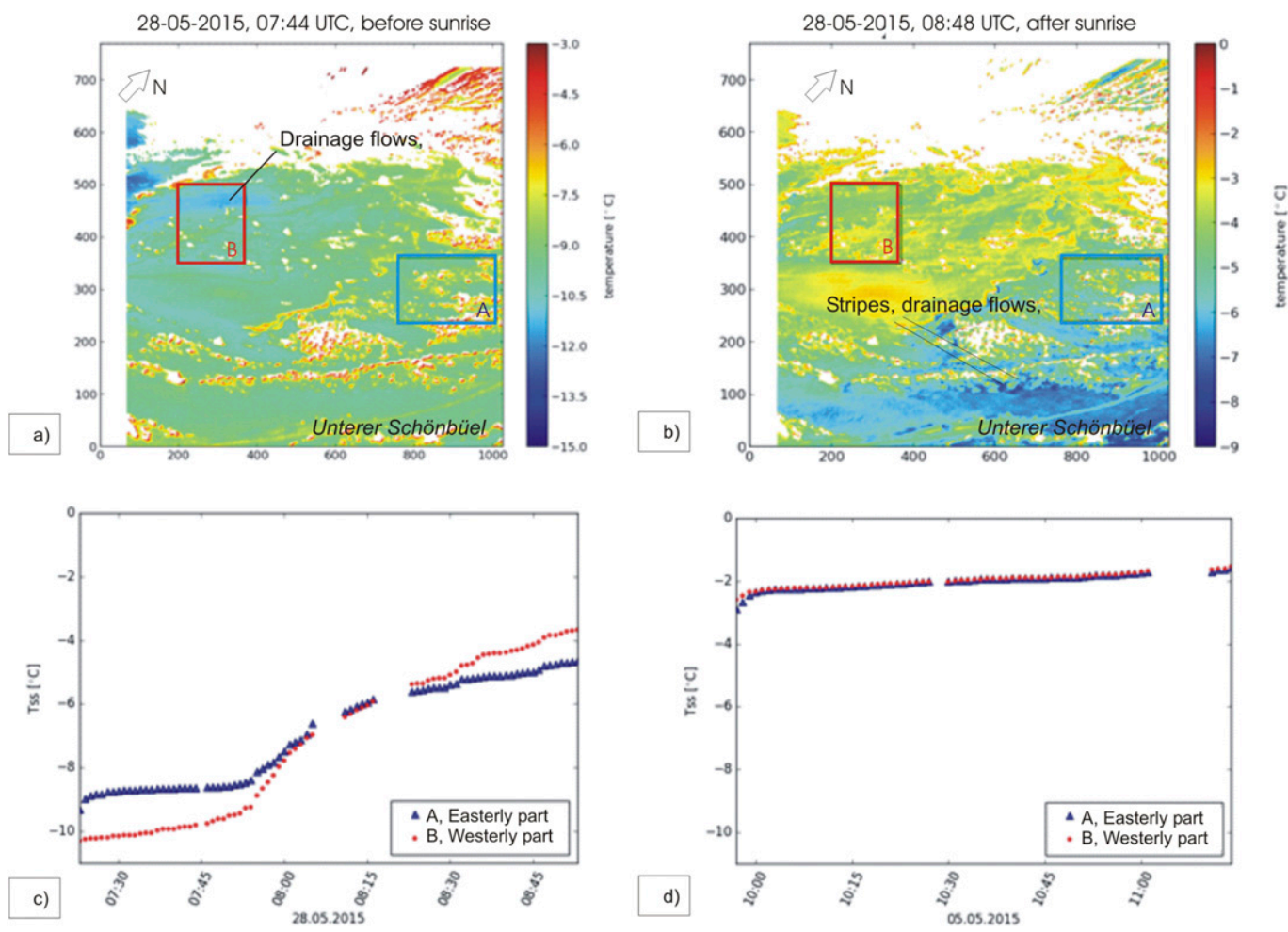

FIG. 6. Snow surface temperature maps (a) before and (b) after sunrise for a thermic day. Note that color codes change between (a) and (b) to optimally illustrate the spatial variability of surface temperatures for both time steps. Snow surface temperature evolution of two areas for (c) the thermic day and (d) synoptically induced southerly flow. The areas selected for averaging snow surface temperatures obtained from the IR camera in (c) and (d) are indicated by blue and red rectangles in (a) and (b). The $x$ and $y$ axes indicate the number of measurement pixels in the corresponding direction.

in surface properties. Conversely, for prevailing northerly flows (including thermally driven up-valley flows and synoptic northerly flows), the flow crosses large already snow-free areas at lower elevations and experiences a step in the surface temperature when approaching the snow-covered area (i.e., 3 May 2014). Locally, the upvalley flow is connected to warm air advection from the snow-free toward the snow-covered areas. For situations favoring large flux footprints of the upper-level sensors (i.e., relatively small friction velocities with high wind velocities as favored by strong atmospheric stability), the flow at the upper-level height (S1 and S2 measured $\sim 1.7 \mathrm{~m}$ in 2014 and $\sim 2.5 \mathrm{~m}$ in 2015 ) is strongly affected by warm-air advection from snow-free areas north to the turbulence stations. The midlevel sensors (S3, S4) are, however, still within a thermal internal layer that develops above the snow. The step in surface temperature between snow-free and snow-covered areas thus induces a strong vertical variability in the turbulent sensible heat flux over snow, even showing different signs of the flux in the first meters above the surface. The strong sensitivity of local atmospheric boundary layer development to wind direction is especially visible for thermic days, such as on 10 and 14 May 2015 (Fig. 7). For those situations, the stable internal boundary layer at the location of the turbulence station appeared to be deep as long as the mountain wind was present. As soon as the wind system changed to an up-valley flow, a shallow stable internal boundary layer developed over the reference snow patch with a depth less than $1.5 \mathrm{~m}$. Sensors installed at heights above the midlevel height of $1.5 \mathrm{~m}$ revealed an unstable flow affected by upwind snow-free areas. At that height, the atmosphere is not affected by the underlying snow-covered ground anymore (Fig. 7). Profiles of sensible turbulent heat fluxes thus show a strong response to the development of the thermal internal boundary layer to prevailing wind direction.

During the third stage of the melting season, the snow cover at the Gletschboden becomes patchy (days marked by PS), and the local snow line progressed to elevations higher than the test site. At this late stage of the melting period, the strong sensitivity of boundary layer development to the prevailing wind direction is not evident anymore. All prevailing wind directions and wind velocities induce the formation of shallow stable 

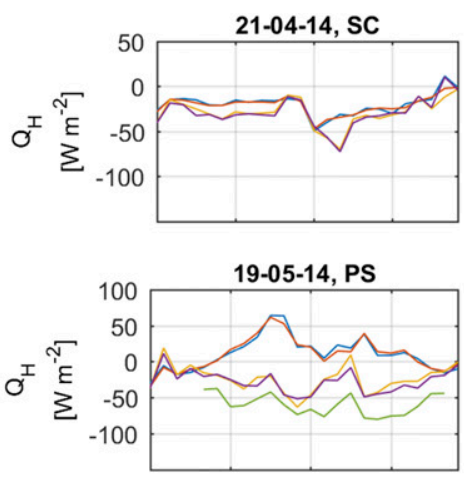

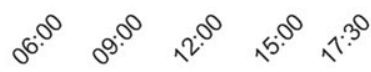

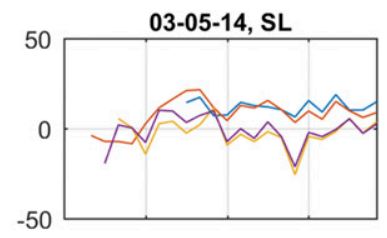

21-05-14, PS

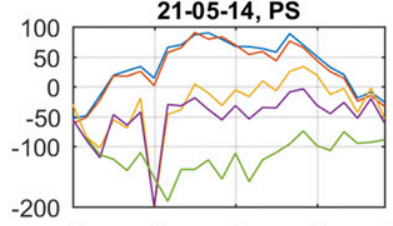

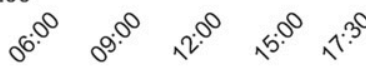

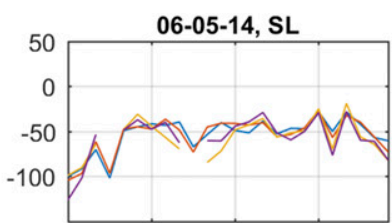

21-05-14, PS

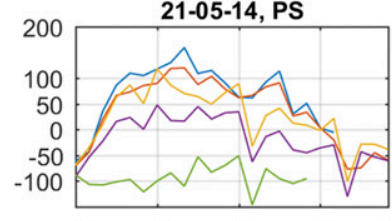

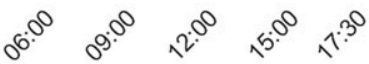

Legend ablation period 2014 S1 $\mathrm{S} 2$
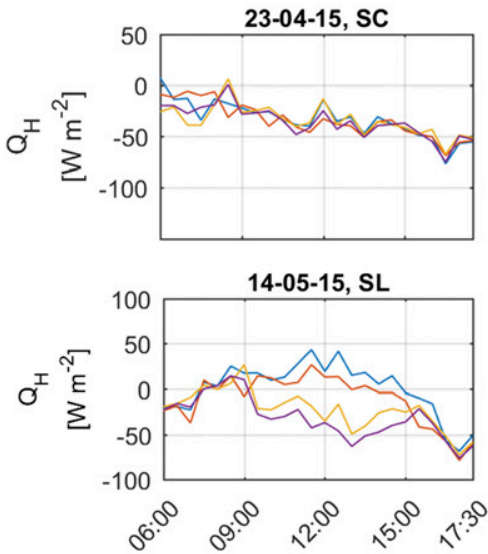

25-04-15, SC

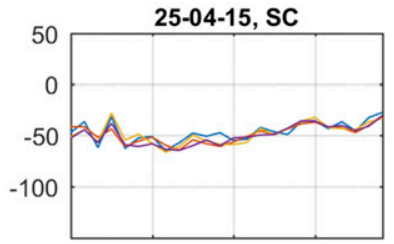

18-05-15, PS

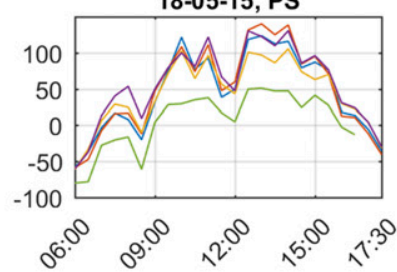

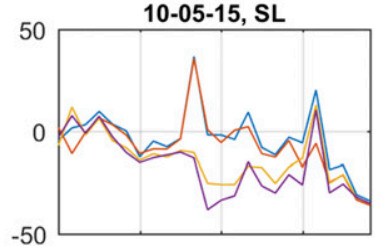

22-05-15, PS

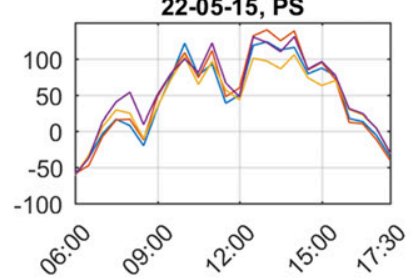

Legend ablation period 2015
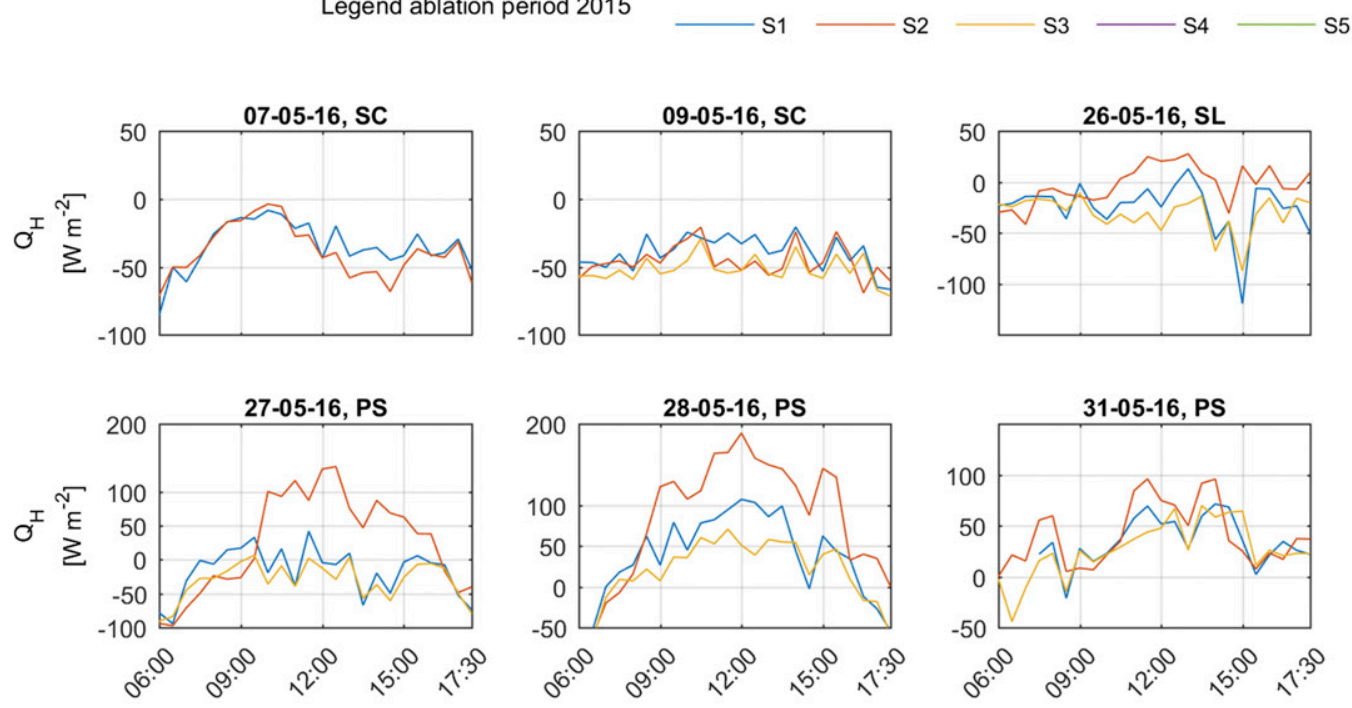

Legend ablation period 2016

S1 over snow

S2 over bare ground

S3 (snow)

FIG. 7. Typical time series of daytime turbulent sensible heat fluxes from 0600 until 1730 UTC obtained during ablation seasons 2014, 2015, and 2016 for different snow cover distributions and for different measurement heights. SC indicates days with a full snow cover at test site Gletschboden. SL indicates days where a sharp snow line was observed at the test site Gleschboden underneath (north to) the turbulence station. PS indicates days when the snow cover at Gletschboden was totally patchy with the snow line clearly above (south to) the turbulence station. Note that sensor S5 was only installed during selected measurement days late in the season. 
internal boundary layers during daytime with a very high vertical variability of turbulent sensible heat fluxes in the first meters above ground. As the snow cover fraction decreases, the footprints of upper- and midlevel sensors become similar or even larger than the short fetch distance over snow (results shown in the following section). The strong decrease in fetch distance over snow involves a decrease of the depth of the stable internal boundary layer at the location of the turbulence stations. Especially for the last measurement days in late May, featuring snow cover fractions lower than $25 \%$, upward heat fluxes are evidenced at all measurement heights despite positive air temperatures over a snow cover staying at its melting point (Fig. 7). The evidence of near-surface upward heat fluxes and positive air temperatures at the same time indicate the presence of a very shallow stable internal boundary layer with a depth lower than $0.3 \mathrm{~m}$. Given the minimum pathlengths of $0.05-0.1 \mathrm{~m}$ of the state-of-the-art ultrasonic anemometers applicable in the field, the supposed downward turbulent sensible heat flux adjacent to the melting snow surface (Whitemann et al. 2001) is not accessible to these measurements any more.

\section{d. Near-surface boundary layer dynamics associated with extreme land surface heterogeneity and upwind source area}

Figure 8 shows turbulent sensible heat fluxes measured by the midlevel and low-level sensors normalized by mean air temperature and plotted against wind speed and friction velocity. We further show the relation between the distance of maximum flux contribution relative to wind fetch distance over snow (xmax/xsnow) for melting days in 2014 and 2015. The distance of maximum flux contribution is defined by the peak of the flux footprint, that is, the distance of the upwind area to which the observation is most sensitive (Schuepp et al. 1990). Fetch distances over snow were determined from snow cover distribution maps. The value of xmax is only an estimation of the effect of upwind areas on the single point measurements. Flux measurements at single locations are affected by the snow cover distribution of the entire upwind zone, and the distribution of flux contribution is typically right skewed, which means that flux measurements are considerably affected by areas larger than xmax. In this analysis, we are interested in sensible turbulent heat fluxes within the stable internal boundary layer approximately representing the heat exchange between the atmosphere and the snow cover. To ensure that measured turbulent sensible heat fluxes are not predominantly affected by bare ground, we excluded days with snow-fetch distances smaller than the distance of maximum flux contribution (xmax/xsnow larger than 1).
We thus only analyze data for snow cover fractions between $94 \%$ and $33 \%$ for ablation season 2014 and from $100 \%$ to $49 \%$ for ablation season 2015 . For all these days, the fetch over snow was larger than the fetch distance of the upwind area to which the sensor S3 is most sensitive (Schuepp et al. 1990). Data obtained in 2016 are excluded from the analyses because of the low number of days with evidence of stable internal boundary layer (SIBL) evolution and lack of a sufficiently large fetch distance over snow at the same time. In the following analyses, we distinguish between days with an evidence of SIBL formation (Fig. 8, diamonds) and days without SIBL formation (Fig. 8, circles) captured by the sensors.

Without SIBL formation, eddy covariance data at the midlevel measurement height show an increase of the downward turbulent sensible heat flux with increasing wind velocity (Fig. 8). For situations with clear evidence of SIBL formation, midlevel measurements (S3) reveal much lower normalized heat fluxes and a significantly smaller increase of the turbulent sensible heat flux with increasing wind velocity (Figs. 8c,d). The significant lower values of turbulent sensible heat fluxes coincide with an increase in the relation between the maximum distance of flux contribution to the fetch distance over snow (Figs. 8e,f). High coefficient values (Figs. 8e,f) indicate large flux footprints (effective upwind source area) sensed by the observations and small fetch distances over snow at the same time. Consequently, large values indicate a significant contribution of the warmer surrounding snow-free areas on the local turbulence field captured by the sensor at the corresponding measurement height and the downwind distance over the reference snow patch. Eddy covariance measurements reveal much smaller downward turbulent sensible heat fluxes at the midlevel measurement height $(\sim 0.7 \mathrm{~m}$ and $\sim 1.5 \mathrm{~m}$ ) if the advection of upwind warm air provokes the formation of a shallow stable internal boundary layer. This is even true for situations with friction velocities high enough to produce enough inertia to mix the boundary layer (Figs. 8a,b). On the contrary, wind situations with very large wind fetch over snow show no significant influence of snow-free areas on the turbulent structure over snow-covered areas. Deep stable layers produce significantly higher normalized turbulent sensible heat fluxes at mid- and upper-level measurement heights early in the ablation season when snow cover fraction is high or for southerly flows with a large fetch over snow.

To minimize the effect of the snow-free areas on the turbulence measurements over snow, we add available measurements at the lowest measurement level above ground (S5) to the analysis featuring much lower 

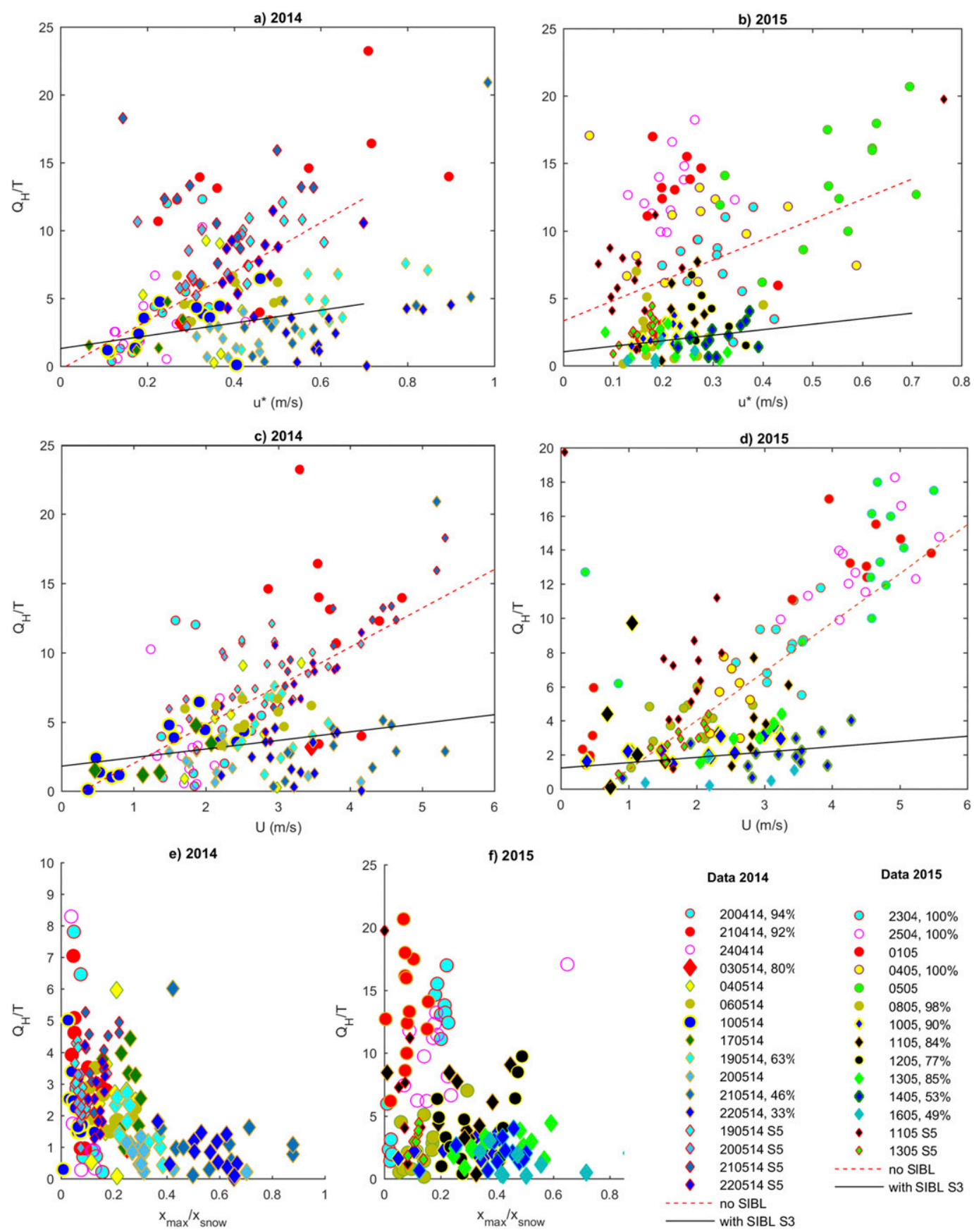

FIG. 8. Turbulent sensible heat fluxes normalized by air temperature plotted against (a),(b) friction velocity and (c),(d) mean wind velocity for data obtained in ablation periods 2014 and 2015. We distinguish between days with evidence of SIBL formation (diamonds) and days without SIBL formation (circles) captured by the sensors. (e),(f) Relation between distances of maximum flux contribution relative to wind fetch distance over snow (xmax/xsnow) is shown.

maximum distances of flux contribution (Figs. 8e,f). Sensors at this measurement height are thus assumed to be less affected by turbulence advected from upwind snow-free areas. While in 2014 data obtained at the 0.3-m measurement level (S5) are available for four analyzed ablation days, only two days with SIBL evidence were recorded by S5 in 2015. The stability parameter and friction velocity measured at the midlevel sensor height during days with SIBL evidence is compared against low-level measurements in Fig. 9. 

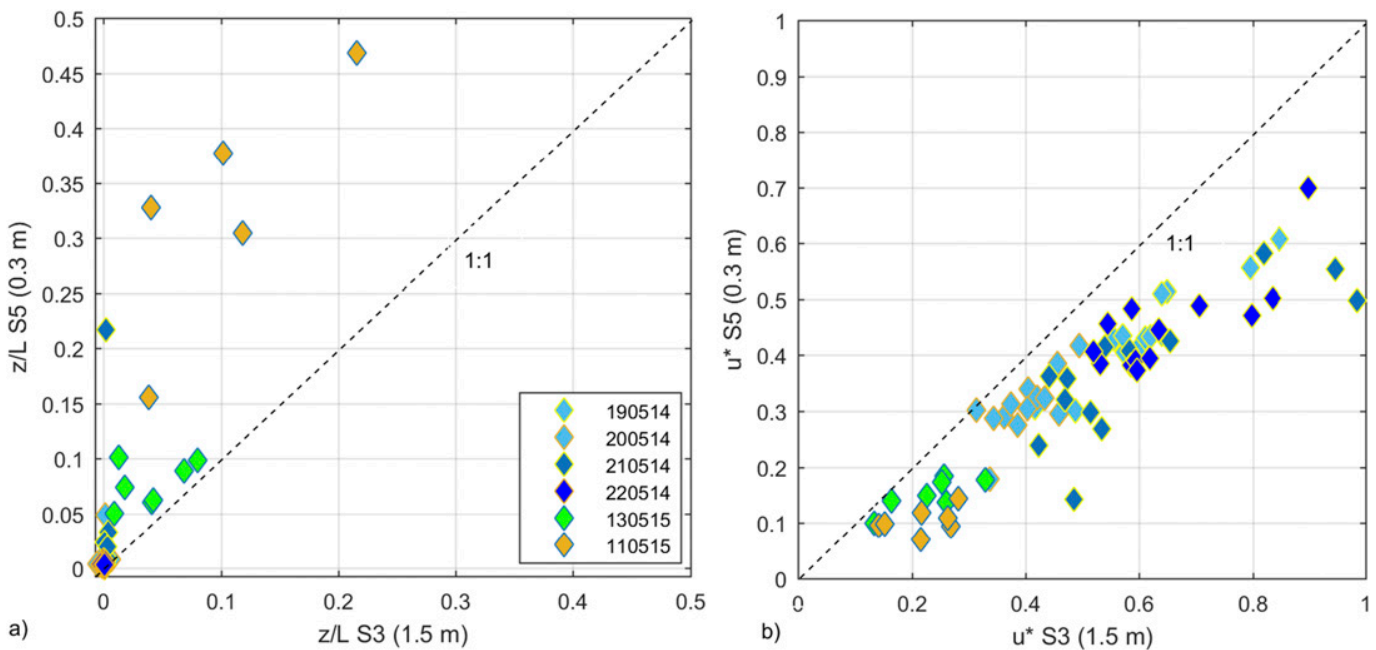

FIG. 9. (a) Stability parameter $z / L$ and (b) friction velocity measured at midlevel sensor S3 plotted against $z / L$ and friction velocity measured at low-level sensor S5.

Turbulent momentum and vertical turbulent heat fluxes within the stable internal boundary layer are expected to increase with decreasing distance to the snow surface (Essery et al. 2006; Mott et al. 2016). Data at $0.3 \mathrm{~m}$ above ground reveal significantly higher normalized turbulent sensible heat fluxes than the upper sensors reflecting the increasing temperature gradients with decreasing distance to the snow surface. At the same time, friction velocities decrease and stability parameters increase toward the 0.3-m measurement level (Fig. 9). Consequently, warm air advection causes a decrease in atmospheric stability and an increase in friction velocity at the upper atmospheric levels of the SIBL. Some of the measurements even show slightly unstable atmospheric conditions at $0.7-1.6 \mathrm{~m}$ above ground. At the same time, atmospheric stability is high within atmospheric layers adjacent to the snow surface, coinciding with a suppression of friction velocity (Fig. 9). The increase in friction velocity at higher levels is a sign of the presence of a shear layer at the upper levels of SIBL associated with a low-level jet.

\section{e. Modeling turbulent heat exchange over an extremely heterogeneous snow cover in spring}

Modeled turbulent heat fluxes using four different stability corrections are compared against measured turbulent heat fluxes in Fig. 10. The analysis of turbulence data measured at different measurement heights showed a strong dependence of heat exchange processes over snow on the fetch distance over snow relative to the footprint at the measurement height. We expect that this strong dependency makes the comparison between modeled sensible heat fluxes at the snow surface and measured sensible heat fluxes at $0.7-2.2 \mathrm{~m}$ above ground strongly sensitive to SIBL occurrence.

During situations with a small vertical variability of downward turbulent heat fluxes within the first meters above ground, model results strongly depend on the applied stability correction as already discussed in Dadic et al. (2013) and Schlögl et al. (2017). Applying heat flux parameterizations of Stearns and Weidner (1993) (modified by Michlmayr et al. 2008) and using a neutrally forced boundary layer lead to predicted turbulent heat fluxes at the surface higher than measured at midlevel sensor height (Fig. 10). Applying the univariate parameterization of heat fluxes (Schlögl et al. 2017) in the energy balance model even leads to smaller predicted turbulent heat fluxes at the snow surface compared to measurements. On the other hand, for situations with strong flux divergence, when the assumption of a constant flux layer totally fails [difference of sensible heat fluxes of two different vertical measurement levels is smaller than $10 \%$ according to Stull (1988)], all models predict much higher sensible heat fluxes at the snow surface than measured at $1.6 \mathrm{~m}$ above the surface. This large bias results from the use of the Monin-Obukhov theory in the model for situations when constant flux layers and fully developed boundary layers do not exist. The difference for situations with SIBL occurrence is significantly reduced if model results are compared against measured sensible heat fluxes at $0.3 \mathrm{~m}$ above ground (Fig. 11).

\section{Discussion}

Turbulence data of three ablation periods show that the ablation period can be divided into three 

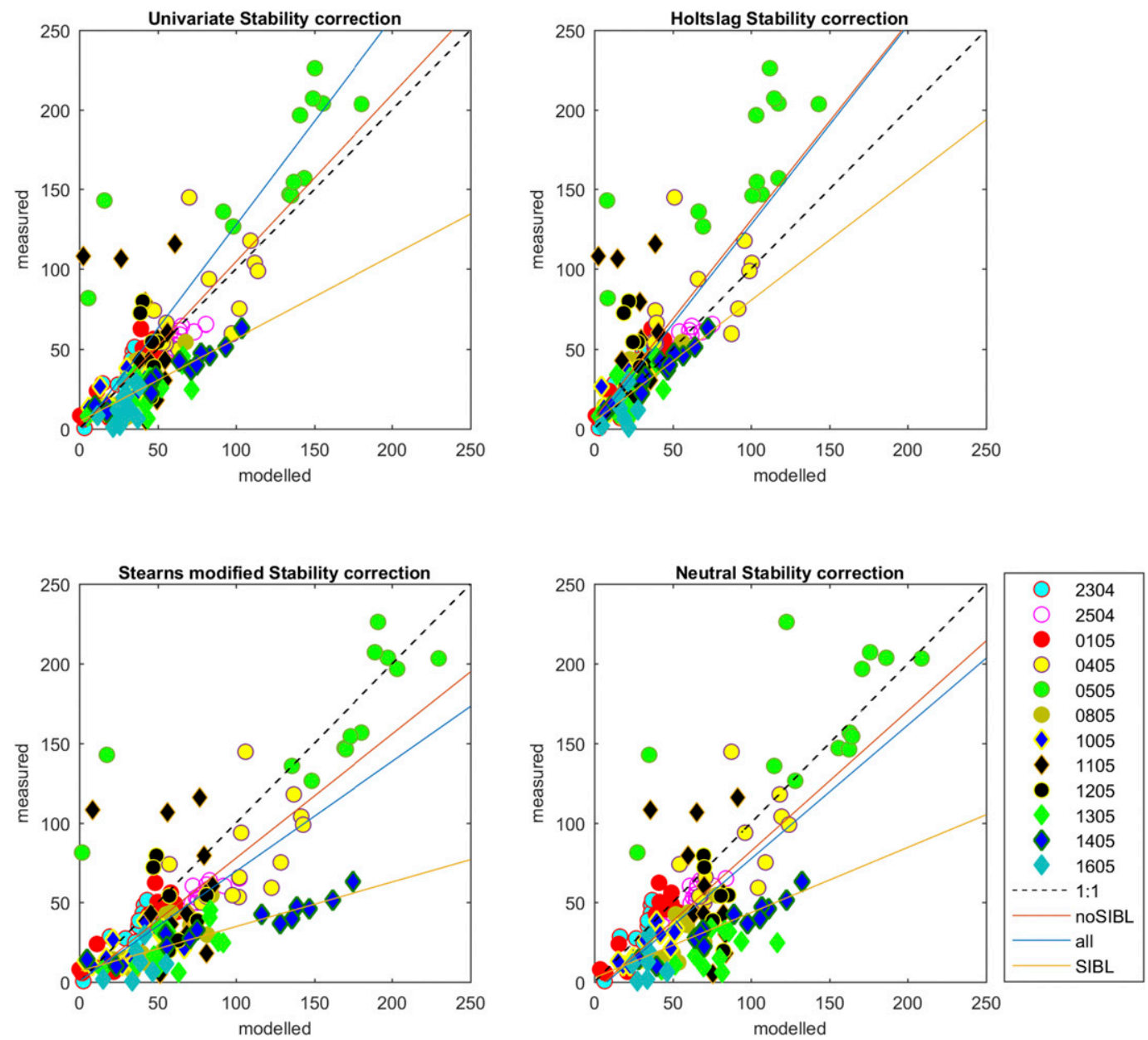

FIG. 10. Comparison between measured midlevel sensible heat flux (S3) and modeled sensible heat flux applying four different stability corrections: Univariate, Holtslag, Stearns modified, and neutral atmosphere.

stages of snow cover distribution, considerably driving the boundary layer development and associated heat exchange at the snow cover: complete snow cover, presence of a clear snow line, and patchy snow cover distribution. Depending on winter snow cover distribution with respect to the elevation difference within the test site, an ablation season is either dominated by the snow line stage (i.e., strong elevation gradient in winter snow accumulation) or the patchy snow cover stage (i.e., small elevation gradient in winter snow accumulation). Typical mountain catchments with strong elevation gradients will typically be dominated by the snow-line stage in the early and middle stage of the ablation period. During this period, profiles of turbulent sensible heat strongly respond to the prevailing wind direction, as already found by Mott et al. (2013), with a similar snow cover distribution featuring a distinct snow line in the investigation area. For these catchments, the patchy snow cover stage is typically restricted to the late stage of the ablation period with a predominance of shallow stable internal boundary layer development above snow for all prevailing wind directions. Conversely, subpolar and polar regions will be dominated by the patchy snow cover stage over a major part of the ablation period. For these regions, which are characterized by small elevation differences and where wind transport of snow leads to often strongly varying snow depths at the beginning of the ablation season (e.g., Liston 1999), thermal internal boundary layers typically develop as soon as the snow becomes patchy and fetch distances over snow become smaller than the flux footprint close to the snow surface. The internal thermal boundary layer development is connected with decoupling of the near-surface air from the warmer surrounding air. Decoupling of near-surface air is revealed by the data showing lower friction velocity and an increase in atmospheric stability close to the ground and high friction velocities at the top of the stable internal 

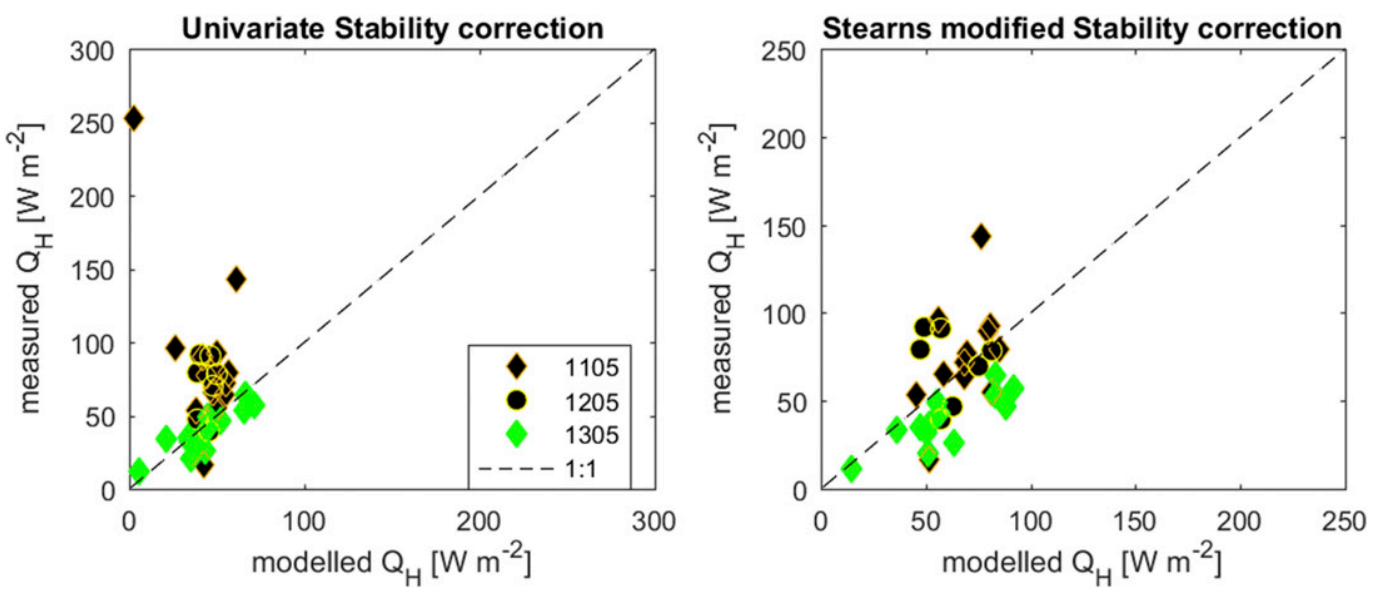

FIG. 11. Comparison between measured low-level sensible heat flux (S5) and modeled sensible turbulent heat flux at the surface applying univariate and modified Stearns stability correction.

boundary layers, indicating the presence of a shear layer at the top of the stable internal boundary layer, similar to what has been hypothesized by Fujita et al. (2010) and what has been observed during wind tunnel experiments (Mott et al. 2016) and numerically investigated over snow patches (Mott et al. 2015).

The experimental and numerical findings show how heterogeneous land surfaces produce very unsteady boundary layers leading to a very high horizontal and vertical variability in turbulent fluxes above snow. The strong contribution of the upwind source area to the profiles of turbulent fluxes over snow has strong implications for hydrological modeling as soon as the snow cover becomes patchy. Measured air temperatures and wind velocities at single points are typically not in balance with the air adjacent to the snow cover, and thus flux predictions will be wrong. The comparison between modeled and measured turbulent sensible heat fluxes highlight the strong sensitivity of eddy covariance measurements over patchy snow cover on the measurement height, the associated footprint, and the snow cover distribution. The difference between model prediction and measured turbulent sensible heat flux increases with decreasing snow cover fraction and with increasing measurement height at the same time (i.e., increasing footprint of sensors). A comparison between predicted turbulent sensible heat fluxes at the snow surface to measured fluxes at measurement heights with footprints similar to the fetch distance over snow leads to model errors. These model errors thus become much larger than for stable conditions over continuous snow covers (e.g., Schlögl et al. 2017), who showed that the largest model errors stem from applying the Monin-Obukhov bulk formulation.
This paper mainly addresses local fluxes and does not try to synthesize the effect on large-scale models, which will be addressed in future work by explicit meteorological modeling. Although there are a number of regional and global model approaches applying subgrid fractional snow cover parameterizations (Roesch et al. 2001; Liston 2004; Takata et al. 2003; Essery 2008; Dutra et al. 2010; Best et al. 2011; Nitta et al. 2014), the interaction between the fractional snow cover and the overlying snow is still highly simplified. Applying simple gradient-flux relationships over patchy snow cover leads to large biases in flux estimates, which need to be addressed in regional models in particular.

\section{Conclusions}

This study presents a unique set of eddy covariance measurements obtained during three entire ablation periods. Turbulence stations consisted of two turbulence towers equipped with five ultrasonic anemometers with different pathlengths suitable to measure turbulence at different atmospheric levels. The combination with high-resolution measurements of snow cover distribution and snow surface temperatures allowed investigation of the highly complex interactions among the gradually increasing heterogeneity of land surface in spring, the near-surface atmospheric boundary layer flow, and turbulent heat exchange between the melting snow cover and the adjacent atmosphere.

The experimental study gives clear evidence on the feedback between the change in land surface variability during the course of an ablation season, the atmospheric boundary layer flow, and the heat exchange over snow. Measurements show that as soon as sun-exposed slopes in the surrounding the test site become snow-free in the 
ablation season, thermal contrasts stimulate the onset of a mountain valley-wind system under fair undisturbed weather. The resulting increase in wind velocity associated with the diurnal up-valley flow significantly drives the diurnal cycle of turbulent heat fluxes above the melting snow cover. Furthermore, temporally and spatially highly resolved snow surface temperature maps obtained from an IR camera indicate the formation of very small-scale drainage flows over long-lasting snow fields significantly changing the local snow cover warming and inducing a high spatial variability of snow surface temperatures, especially in the morning hours. These experiments confirm earlier numerical studies at different scales (Segal et al. 1991; Mott et al. 2015) that suggested the development of thermally driven boundary layer flows over large snow patches and an associated effect on the local energy balance over snow for fair weather conditions.

Experimental results impressively demonstrate the strong influence of land surface variability on the turbulent flux profiles measured at single points. Snow cover distribution is shown to be of vital importance for the frequency of thermal boundary layer development. We have identified three stages of snow cover distribution considerably driving the boundary layer development during the ablation period: complete snow cover, presence of a clear snow line, and patchy snow cover distribution. An ablation season is either dominated by the snow line stage or the patchy snow cover stage. The snow line stage is dominant in regions with a strong elevation gradient in winter snow accumulation or large altitudinal differences within the test site. The patchy snow cover stage is dominant in areas characterized by a small elevation gradient in winter snow accumulation or a small altitudinal difference within the test site. Deep stable boundary layers are predominantly found as long as the snow cover is complete. As soon as a clear snow line progresses from lower elevations toward the test site, the development of unsteady and shallow thermal boundary layers is strongly dependent on the prevailing wind direction. Typically, in the late stage of a melting period, when the snow cover becomes patchy, thermal boundary layers develop for all prevailing wind directions and the internal boundary layer height decreases to lower than $0.3 \mathrm{~m}$.

Profiles of turbulent sensible heat exchange over a long-lasting snow patch clearly reveal a locally unsteady boundary layer during the last two stages of a melting period (snow line and patchy snow cover). The formation of thermal internal boundary layers at the Gletschboden is favored during situations forcing the advection of warmer air from snow-free toward snow-covered areas. Data reveal turbulent sensible heat flux profiles featuring a high flux divergence, even showing different signs of the fluxes in the first $2 \mathrm{~m}$ above the ground. Eddy covariance measurements at $1.5 \mathrm{~m}$ above ground reveal significantly smaller downward turbulent heat fluxes for situations with evidence of stable internal boundary layer development. For these situations, the sensible heat fluxes increased at the lowest atmospheric levels above snow, revealing a very shallow layer adjacent to the snow cover decoupled from the warm-air advection above. At the same time, friction velocities are shown to be significantly smaller at the lowest atmospheric level $(0.3 \mathrm{~m}$ above surface), coinciding with a strong increase in atmospheric stability there. The increase in friction velocity at higher atmospheric levels is an indication for the presence of a shear layer at the top of the stable internal boundary layer similar to what has been observed during wind tunnel experiments (Mott et al. 2016) and for numerical investigations over snow patches (Mott et al. 2015).

Experimental findings show that extremely heterogeneous land surfaces induce high horizontal and vertical variability in turbulent fluxes above snow. The strong contribution of the upwind snow-free areas on the heat exchange between snow cover and the overlying atmosphere has strong implications for hydrological modeling covering an entire ablation season. Using simple parameterizations of subgrid snow cover fractions and applying simple gradient-flux relationships at the same time might lead to large biases in flux estimates that need to be addressed by regional models in the future.

Acknowledgments. We thank Christoph Thomas and Yves Bühler for sharing their expertise in eddy covariance postprocessing methods and infrared measurements. We thank Franziska Gerber, Louis Queno, Christian Sommer, Prisco Frei, and Urs Kühne for assisting during the field work. The work presented here is mainly supported by the Swiss National Science Foundation SNF (Grant 200021_150146).

\section{REFERENCES}

Bavay, M., M. Lehning, T. Jonas, and H. Löwe, 2009: Simulations of future snow cover and discharge in Alpine headwater catchments. Hydrol. Processes, 23, 95-108, doi:10.1002/hyp.7195.

Best, M. J., and Coauthors, 2011: The Joint UK Land Environment Simulator (JULES), model description-Part 1: Energy and water fluxes. Geosci. Model Dev., 4, 677-699, doi:10.5194/gmd-4-677-2011.

Cohen, J., and D. Rind, 1991: The effect of snow cover on climate. J. Climate, 4, 698-706, doi:10.1175/1520-0442(1991)004<0689: TEOSCO $>2.0 . \mathrm{CO} ; 2$.

Dadic, R., R. Mott, M. Lehning, and P. Burlando, 2010: Wind influence on snow depth distribution and accumulation over glaciers. J. Geophys. Res., 115, F01012, doi:10.1029/2009JF001261. 
,,--- M. Carenzo, B. Anderson, and A. Mackintosh, 2013: Sensitivity of turbulent fluxes to wind speed over snow surfaces in different climatic settings. Adv. Water Resour., 55 , 178-189, doi:10.1016/j.advwatres.2012.06.010.

de Vrese, P., J.-P. Schulz, and S. Hagemann, 2016: On the representation of heterogeneity in land-surface-atmosphere coupling. Bound.-Layer Meteor., 160, 157-183, doi:10.1007/ s10546-016-0133-1.

Dutra, E., G. Balsamo, P. Viterbo, P. M. A. Miranda, A. Beljaars, C. Schär, and K. Elder, 2010: An improved snow scheme for the ECMWF land surface model: Description and offline validation. J. Hydrometeor., 11, 899-916, doi:10.1175/2010JHM1249.1.

Essery, R., 1999: Parameterization of heterogeneous snowmelt Theor. Appl. Climatol., 62, 25-30, doi:10.1007/s007040050071. , 2008: Snow parameterization in GCMs. Snow and Climate: Physical Processes, Surface Energy Exchange and Modeling, R. L. Armstrong and E. Brun, Eds., Cambridge University Press, 145-156.

_, R. Granger, and J. W. Pomeroy, 2006: Boundary-layer growth and advection of heat over snow and soil patches: Modelling and parameterization. Hydrol. Processes, 20, 953-967, doi:10.1002/hyp.6122.

Foken, T., M. Göckede, M. Mauder, L. Mahrt, B. Amiro, and J. Munger, 2004: Post-field data quality control. Handbook of Micrometeorology: A Guide for Surface Flux Measurement and Analysis, X. Lee, W. Massman, and B. Law, Eds., Kluwer, 181-208, doi:10.1007/1-4020-2265-4.

Fujita, K., K. Hiyama, H. Iida, and Y. Ageta, 2010: Self-regulated fluctuations in the ablation of a snow patch over four decades. Water Resour. Res., 46, W11541, doi:10.1029/2009WR008383.

Gerber, F., M. Lehning, S. W. Hoch, and R. Mott, 2017: A closeridge small-scale atmospheric flow field and its influence on snow accumulation. J. Geophys. Res. Atmos., 122, 7737-7754, doi:10.1002/2016JD026258

Glazirin, G. E., Y. Kodama, and T. Ohata, 2004: Stability of drifting snow-type perennial snow patches. Bull. Glaciol. Res., 21, 1-8.

Granger, R. J., R. Essery, and J. Pomeroy, 2006: Boundary-layer growth over snow and soil patches: Field observations. Hydrol. Processes, 20, 943-951, doi:10.1002/hyp.6123.

Griessinger, N., J. Seibert, J. Magnusson, and T. Jonas, 2016: Assessing the benefit of snow data assimilation for runoff modeling in Alpine catchments. Hydrol. Earth Syst. Sci., 20, 3895-3905, doi:10.5194/hess-20-3895-2016.

Grünewald, T., M. Schirmer, R. Mott, and M. Lehning, 2010: Spatial and temporal variability of snow depth and ablation rates in a small mountain catchment. Cryosphere, 4, 215-225, doi:10.5194/tc-4-215-2010.

Harder, P., J. W. Pomeroy, and W. Helgason, 2017: Local scale advection of sensible and latent heat during snowmelt. Geophys. Res. Lett., 44, doi:10.1002/2017GL074394, in press.

Hennemuth, B., 1986: Thermal asymmetry and cross-valley circulation in a small alpine valley. Bound.-Layer Meteor., 36, 371-394, doi:10.1007/BF00118338.

— Dischma valley. Meteor. Atmos. Phys., 34, 97-119.

— , and H. Schmidt, 1985: Wind phenomena in the Dischma valley during DISKUS. Arch. Meteor. Geophys. Bioclimatol., B35, 361-387, doi:10.1007/BF02334490.

Hori, M., T. Aoki, T. Tanikawa, A. Hachikubo, K. Sugiura, K. Kuchiki, and M. Niwano, 2013: Modeling angular-dependent spectral emissivity of snow and ice in the thermal infrared atmospheric window. Appl. Opt., 52, 7243-7255, doi:10.1364/ A 0.52 .007243 .
Idso, S. B., 1981: A set of equations for full spectrum and 8- to $14-\mu \mathrm{m}$ and $10.5-$ to $12.5-\mu \mathrm{m}$ thermal radiation from cloudless skies. Water Resour. Res., 17, 295-304, doi:10.1029/WR017i002p00295.

Johnson, R. H., G. S. Young, and J. J. Toth, 1984: Mesoscale weather effects of variable snow cover over northeast Colorado. Mon. Wea. Rev., 112, 1141-1152, doi:10.1175/ 1520-0493(1984)112<1141:MWEOVS>2.0.CO;2.

Lehning, M., 2013: Snow-atmosphere interactions and hydrological consequences. Adv. Water Resour., 55, 1-3, doi:10.1016/j.advwatres.2013.02.001.

, I. Völksch, D. Gustafsson, T. A. Nguyen, M. Stähli, and M. Zappa, 2006: ALPINE3D: A detailed model of mountain surface processes and its application to snow hydrology. Hydrol. Processes, 20, 2111-2128, doi:10.1002/hyp.6204.

Letcher, T. W., and J. R. Minder, 2015: Characterization of the simulated regional snow albedo feedback using a regional climate model over complex terrain. J. Climate, 28, 7576-7595, doi:10.1175/JCLI-D-15-0166.1.

_, and — 2017: The simulated response of diurnal mountain winds to regionally enhanced warming caused by the snow albedo feedback. J. Atmos. Sci., 74, 49-67, doi:10.1175/ JAS-D-16-0158.1.

Liston, G. E., 1995: Local advection of momentum, heat and moisture during the melt of patchy snow covers. J. Appl. Meteor., 34, 1705-1715, doi:10.1175/1520-0450-34.7.1705.

1999: Interrelationships among snow distribution, snowmelt, and snow cover depletion: Implications for atmospheric, hydrologic, and ecologic modeling. J. Appl. Meteor., 38, 1474-1487, doi:10.1175/1520-0450(1999)038<1474: IASDSA $>2.0 . \mathrm{CO} ; 2$.

2004: Representing subgrid snow cover heterogeneities in regional and global models. J. Climate, 17, 1381-1397, doi:10.1175/1520-0442(2004)017<1381:RSSCHI>2.0.CO;2.

Marsh, P., R. Essery, N. Neumann, and J. W. Pomeroy, 1999: Model estimates of local advection of sensible heat over a patchy snow cover. Interactions between the Cryosphere, Climate and Greenhouse Gases, M. Tranter, Ed., IAHS Publ. 256, 103-110.

Michlmayr, G., M. Lehning, G. Koboltschnig, H. Holzmann, M. Zappa, R. Mott, and W. Schöner, 2008: Application of the Alpine 3D model for glacier mass balance and glacier runoff studies at Goldbergkees, Austria. Hydrol. Processes, 22, 3941-3949, doi:10.1002/hyp.7102.

Moore, C. J., 1986: Frequency response corrections for eddy correlation systems. Bound.-Layer Meteor., 37, 17-35, doi:10.1007/BF00122754

Mott, R., L. Egli, T. Grünewald, N. Dawes, C. Manes, M. Bavay, and M. Lehning, 2011: Micrometeorological processes driving snow ablation in an Alpine catchment. Cryosphere, 5, 1083-1098, doi:10.5194/tc-5-1083-2011. C. Gromke, T. Grünewald, and M. Lehning, 2013: Relative importance of advective heat transport and boundary layer decoupling in the melt dynamics of a patchy snow cover. $A d v$. Water Resour., 55, 88-97, doi:10.1016/j.advwatres.2012.03.001.

, D. E. Scipión, M. Schneebeli, N. Dawes, A. Berne, and M. Lehning, 2014: Orographic effects on snow deposition patterns in mountainous terrain. J. Geophys. Res. Atmos., 119, 1363-1385, doi:10.1002/2013JD019880.

_- M. Daniels, and M. Lehning, 2015: Atmospheric flow development and associated changes in turbulent sensible heat flux over a patchy mountain snow cover. J. Hydrometeor., 16, 1315-1340, doi:10.1175/JHM-D-14-0036.1.

E. Paterna, S. Horender, P. Crivelli, and M. Lehning, 2016: Wind tunnel experiments: Cold-air pooling and atmospheric 
decoupling above a melting snow patch. Cryosphere, 10, 445-458, doi:10.5194/tc-10-445-2016.

Nitta, T., and Coauthors, 2014: Representing variability in subgrid snow cover and snow depth in a global land model: Offline validation. J. Climate, 27, 3318-3330, doi:10.1175/JCLI-D-13-00310.1.

Odegard, R. S., A. Nesje, K. Isaksen, L. M. Andreassen, T. Eiken, M. Schwikowski, and C. Uglierri, 2017: Climate change threatens archaeologically significant ice patches: Insights into their age, internal structure, mass balance and climate sensitivity. Cryopshere, 11, 17-32, doi:10.5194/tc-11-17-2017.

Pohl, S., P. Marsh, and G. E. Liston, 2006: Spatial-temporal variability in turbulent fluxes during spring snowmelt. Arct. Antarct. Alp. Res., 38, 136-146, http://www.jstor.org/stable/4095836.

Prokop, A., M. Schirmer, M. Rub, M. Lehning, and M. Stocker, 2008: A comparison of measurement methods: Terrestrial laser scanning, tachymetry and snow probing, for the determination of spatial snow depth distribution on slopes. Ann. Glaciol., 49, 210-216, doi:10.3189/172756408787814726.

Randall, D. A., and Coauthors, 1994: Analysis of snow feedbacks in 14 general circulation models. J. Geophys. Res., 99, 20 757-20 771, doi:10.1029/94JD01633.

Roesch, A., M. Wild, H. Gilgen, and A. Ohmura, 2001: A snow cover fraction parametrization for the ECHAM4 GCM. Climate Dyn., 17, 933-946, doi:10.1007/s003820100153.

Sauter, T., and F. Obleitner, 2015: Assessing the uncertainty of glacier mass-balance simulations in the European Arctic based on variance decomposition. Geosci. Model Dev., 8, 3911-3928, doi:10.5194/gmd-8-3911-2015.

Schaffhauser, A., M. Adams, R. Fromm, P. Jörg, G. Luzi, L. Noferini, and R. Sailer, 2008: Remote sensing based retrieval of snow cover properties. Cold Reg. Sci. Technol., 54, 164-175, doi:10.1016/j.coldregions.2008.07.007.

Schlögl, S., M. Lehning, K. Nishimura, H. Huwald, N. J. Cullen, and R. Mott, 2017: How do stability corrections perform in the stable boundary layer over snow? Bound.-Layer Meteor., 165, 161-180, doi:10.1007/s10546-017-0262-1.

Schuepp, P. H., M. Y. Leclerc, J. I. MacPherson, and R. L. Desjardins, 1990: Footprint prediction of scalar fluxes from analytical solutions of the diffusion equation. Bound.-Layer Meteor., 50 , 255-373, doi:10.1007/BF00120530.

Segal, M., J. R. Garrat, R. A. Pielke, and Z. Ye, 1991: Scaling and numerical model evaluation of snow cover effects on the generation and modification of daytime mesoscale circulations. J. Atmos. Sci., 48, 1024-1041, doi:10.1175/ 1520-0469(1991)048<1024:SANMEO>2.0.CO;2.

Sommer, C. G., M. Lehning, and R. Mott, 2015: Snow in a very steep rock face: Accumulation and redistribution during and after a snowfall event. Front. Earth Sci., 3, 73, doi:10.3389/ feart.2015.00073.

Stearns, C. R., and G. A. Weidner, 1993: Sensible and latent heat flux estimates in Antarctica. Antarct. Res. Ser., 61, 109-138, doi:10.1029/AR061p0109.

Stull, R. B., 1988: An Introduction to Boundary Layer Meteorology. Atmospheric ad Oceanographic Sciences Library, Vol. 13, Springer, 670 pp., doi:10.1007/978-94-009-3027-8.

Tabler, R. D., 1975: Predicting profiles of snowdrifts in topographic catchments. Proc. 43rd Annual Western Snow Conf., Coronado, CA, Western Snow Conference, 87-97, https://westernsnowconference.org/node/1073.

Takata, K., S. Emori, and T. Watanabe, 2003: Development of the minimal advanced treatments of surface interaction and runoff. Global Planet. Change, 38, 209-222, doi:10.1016/ S0921-8181(03)00030-4.

Taylor, C. M., R. J. Harding, R. A. Pielke Sr., P. L. Vidale, R. L. Walko, and J. W. Pomeroy, 1998: Snow breezes in the boreal forest. J. Geophys. Res., 103, 23 087-23 101, doi:10.1029/98JD02004.

Thomas, C. K., B. E. Law, J. Irvine, J. G. Martin, J. C. Pettijohn, and K. J. Davis, 2009: Seasonal hydrology explains interannual and seasonal variation in carbon and water exchange in a semiarid mature ponderosa pine forest in central Oregon. J. Geophys. Res., 114, G04006, doi:10.1029/2009JG001010.

Urfer-Henneberger, C., and H. Turner, 1982: Bodennahes Windsystem und Temperaturgradienten bei verschiedenen Wetterlagen in einem von Süden nach Norden führenden V-förmigen Alpental. Arch. Meteor. Geophys. Bioclimatol., B31, 253-271, doi:10.1007/BF02278296.

Vickers, D., and L. Mahrt, 1997: Quality control and flux sampling problems for tower and aircraft data. J. Atmos. Oceanic Technol., 14, 512-526, doi:10.1175/1520-0426(1997)014<0512: QCAFSP $>2.0 . C O ; 2$.

Whiteman, C. D., S. Zhong, W. J. Shaw, J. M. Hubbe, X. Bian, and J. Mittelstadt, 2001: Cold pools in the Columbia basin. Wea. Forecasting, 16, 432-447, doi:10.1175/1520-0434(2001)016<0432: CPITCB $>2.0 . \mathrm{CO} ; 2$. 